\title{
Effects of iron nano-complex and Fe-EDDHA on bioactive compounds and nutrient status of purslane plants
}

\author{
Vahid Tavallali \\ Department of Agriculture, Payame Noor University (PNU), P.O. Box: 19395-3697 Tehran, Iran \\ Received January 20, 2018; accepted June 12, 2018
}

\begin{abstract}
Nanoparticles serve as a new fertilization method utilised in agriculture, and their potential effect on medicinal crops has been mainly unexplored. In the present study, using ultrasonic irradiations, a novel nano-sized iron complex has been prepared from aminolevulinic acid and iron (III) nitrate under greenhouse conditions. The obtained Fe nano-sized energy dispersive X-ray spectroscopy complex has been characterized by two methods, i.e. Fourier-transform infrared spectroscopy and spectra. The morphology and size of the nano-complex were also determined using transmission electron micrographs and showed an acceptable size in the nano range $(5-25 \mathrm{~nm})$. In this work, purslane plants were supplied with Fe (III)-aminolevulinic acid as a new nano-sized complex and Fe-EDDHA. The mineral nutrient concentrations, total phenolic, ascorbic acid contents and antioxidant activity were the highest in the plants treated with the Fe-ALA nano-complex. Catechin was the predominant phenolic compound in all treated plants. The Fe nano-complex at the rate of $0.2 \%$ induced extra high-value phenolic compounds. The shoot $\mathrm{Fe}, \mathrm{Zn}, \mathrm{N}, \mathrm{Mg}, \mathrm{Ca}$ and $\mathrm{K}$ contents were also higher in the plants treated with the Fe nano-complex than in both the control group and the plants treated with Fe-EDDHA. In general, the nutritional and pharmaceutical quality of Portulaca oleracea L. improved when using the nano-sized Fe-ALA complex as a new iron source.

Key w ord s: antioxidant activity, iron, mineral nutrients, nano chelate, purslane, polyphenolic content
\end{abstract}

\section{INTRODUCTION}

Nowadays, nanotechnology is one of the areas of science which have come to play an important role in chemistry and agriculture. In other words, nanotechnology has opened new opportunities of reducing the environmental protection cost and improving nutrient use efficiency (Naderi and Danesh Shahraki, 2011). Nanostructures are one of the most important branches of nanotechnology.

*Corresponding author e-mail: vtavallali@gmail.com
Among all existing nanostructures, nanoparticles, which have a very high surface area to volume ratio, are of great scientific interest. The synthesis of nano-sized metal complexes has received great attention in recent years, owing to their vast applications and unique properties in various sciences. Moreover, the green synthesis of these nanocomplexes has attracted more attention for environmental remediation (Wei et al., 2016).

Antioxidants, which are naturally found in vegetables, along with different phytochemicals, have gained popularity due to the prevalence of phenolic compounds, and they are considered very suitable for decreasing oxidative stress. Therefore, they are recognized as the dominating factor in the antioxidant activity of plants. Due to their hydrogen contribution, antioxidants are able to scavenge free radicals before they begin to damage biological parts and cells. Therefore, they are deemed necessary for the wealth and verification of an ideal wellbeing (Percival, 1998). Plants are made up of differing compounds, such as flavonoids (anthocyanins, flavones, flavonols, and so forth) and some non-flavonoid categories (phenolic acids, lignins, stilbenes, terpenoids, and so on) constituting phenolic components. The aforementioned compounds differ in terms of the structure including, for instance, the phenolic hydroxyl group position and their corresponding number, triggering disparity in their antioxidative role (Knekt et al., 1996).

The common purslane (Portulaca oleracea L.) from the Portulacaceae family contains many species (their number exceeding 120) that are succulent herbs and shrubs. Various countries use the aerial plant parts as antiseptics, febrifuges, diuretics, vermifuges and antispasmodics (Xiang et al.,

(C) 2018 Institute of Agrophysics, Polish Academy of Sciences 
2005). In the Middle East countries, Portulaca oleraceae is eagerly eaten as a vegetable. In terms of consumption, interest is usually drawn to its leaves and stems as they are edible and succulent, and have both an acidic and salty taste, which is very notable in Spinacia oleracea L. It is common, self-compatible and rapidly-growing, and it turns out expanded amounts of seeds (Liu et al., 2000). Plentiful purslane collections are cultivated in a widespread diversity of districts and climates. It is known to have higher values of nutrition than other vegetables, acting as a boundless source of ascorbic acid, phenolics and antioxidants (Liu et al., 2000).

The nutrition-related quality of these plants forms one of the causes that influence the chemical arrangements, and the quality of pharmaceutical plants and vegetables, with microelements that play a significant role in their processing (Yousefzadeh and Sabaghnia, 2016). Their availability and price rate, coupled with the efficiency of domestic fertilizer sources that employ modern technologies, is a twofold benefit. They are economical to produce, resulting in a decreased fertilizer loss and a significant reduction in environmental pollution. Iron has played many roles in the activity of several antioxidant enzymes, as well as in chlorophyll and thylakoid synthesis, chloroplast development, RNA synthesis and photosystems performance enhancement (Ghasemi et al., 2014). Synthetic Fe-chelates, including Fe-EDTA and Fe-DTPA, are currently utilized to raise the obtainability of $\mathrm{Fe}$ in soils and to maintain its necessary amount (Vadas et al., 2007). Synthetic Fe-chelates are operative bases of Fe, particularly in alkaline and calcareous soil (Rodriguez-Lucena et al., 2010). Fe (III)-EDTA chelate is the prevalent iron source used in agriculture (Vadas et al., 2007). Even though EDTA preserves the solubility of $\mathrm{Fe}$, after metal absorption by the plant, the free ligand concentration is likely to increase, which leads to a higher likelihood of the complex formation of free ligands with various micro elements (such as $\mathrm{Cu}, \mathrm{Mn}$, and $\mathrm{Zn}$ ), hence decreasing the availability and metal absorption by the plant (Vadas et al., 2007). Furthermore, EDTA and DTPA chelates are sensitive to photodegradation. The halflife of Fe-DTPA and Fe-EDTA chelates, when exposed to severe sunlight conditions, lasts eleven and eight minutes, accordingly (Metsarinne et al., 2004). The photodegradation of synthetic ligands leads to the creation of a kind of compounds that are detrimental to plants growth and reduce the availability of $\mathrm{Fe}$ through its precipitation (Metsarinne et al., 2004; Vadas et al., 2007).

In this study, we tested the nano Fe-amino chelate, synthesized through the complexation process of $\mathrm{Fe}$ with certain 5-aminolevulinic acid, as a novel $\mathrm{Fe}$ source for soil treatment. Amino acids organise $\mathrm{Fe}$ ions via their own amine and carboxylate groups. Moreover, $\mathrm{Fe}$-amino acid chelates are steady in the soil (Ghasemi et al., 2014).
There is a shortage of data describing how the blend of amino acids and $\mathrm{Fe}$, and their nanoscale quality, affect therapeutic and aromatic plants. Nanoparticles, which have a broad surface territory and are negligible in size, are needed in order to induce suitable chances as plant fertilizers. Both sulphate salts and chelated $\mathrm{Fe}$ (with ethylene diamine tetra acetic acid, EDTA) are used in soil and foliar applications by farmers in spite of their low efficacy. Similarly, the hypothesis was that nano chelate as a novel Fe compost source is highly effective in developing polyphenol substances and in enhancing the antioxidant activity of plants, when used in medicine. This hypothesis was tested by analysing the impact of foliar use of the synthetic Fe-amino nano chelate, i.e. $\left[\mathrm{Fe}(\mathrm{ALA})_{3}\right]$ on the growth, phenolic compounds, antioxidant activity and nutrient status of purslane plants, in an effort to improve their application for the human consumption.

\section{MATERIALS AND METHODS}

Analytical grade chemicals were utilized as bought, sans extra purification. For nanoparticles characterization, transmission electron micrographs (TEM) were obtained by means of a TEM device (100 kV Philips, EM208). The EDX and FTIR spectra were obtained using a SEM-EDX analyzer (Tescan Vega II, with a Rontec detector) and a Tensor II FTIR spectrometer, respectively.

For the synthesis of the nano-sized Fe-ALA complex, firstly at room temperature, 5 -aminolevulinic acid ( $2 \mathrm{mmol})$ was dissolved in deionised water $(5 \mathrm{ml})$. A solution of $\mathrm{Fe}\left(\mathrm{NO}_{3}\right)_{3}(1 \mathrm{mmol})$ in $3 \mathrm{ml}$ distilled water was then added. The chemical reaction was subsequently exposed to sonication, utilizing an ultrasonic probe, and the whole mixture was prepared under stable oscillation of $90 \%$ for $30 \mathrm{~min}$ in standard atmosphere. The mixture was then chilled to ambient temperature and the solvent was evaporated. After the solution was dried by overnight air flow, and subsequently exposed to vacuum conditions for $18 \mathrm{~h}$, a dark brown powder was obtained.

The greenhouse trial was completed at the Shiraz Payame Noor University, situated in Golestan town $\left(29^{\circ}\right.$ $36^{\prime} \mathrm{N}$ and $52^{\circ} 32^{\prime} \mathrm{E}, 1490 \mathrm{~m}$ above sea level). The soil used in this study was a fine topsoil loam taken from 0 to $30 \mathrm{~cm}$ of virgin soil. The physicochemical properties of the soil were as follows: $\mathrm{pH}$ paste: 7.1, $\mathrm{EC}_{\mathrm{e}}: 1.2 \mathrm{dS} \mathrm{m}^{-1}$, CEC: 10 $\mathrm{Cmc} \mathrm{kg}^{-1}$, organic C: $8.9 \mathrm{~g} \mathrm{~kg}^{-1}$ soil, $\mathrm{N}: 0.07 \%$, P: $13 \mathrm{mg}$ $\mathrm{kg}^{-1}$ soil, $\mathrm{K}: 59 \mathrm{mg} \mathrm{kg}^{-1}$ soil, DTPA-extractable Fe: $2.21 \mathrm{mg}$ $\mathrm{kg}^{-1}$ soil. Regarding the basic acute rate for the DTPAextractable soil Fe $\left(2 \mathrm{mg} \mathrm{kg}^{-1}\right)$ (Fageria et al., 1990), the soil was not extremely deficient in Fe. Nitrogen and $\mathrm{P}$ at the concentration of $50 \mathrm{mg} \mathrm{kg}^{-1}$ soil, and $\mathrm{Cu}, \mathrm{Zn}$ and $\mathrm{Mn}$ at the concentration of $5 \mathrm{mg} \mathrm{kg}^{-1}$ soil were applied in a uniform manner to the soil, as $\mathrm{NH}_{4} \mathrm{NO}_{3}, \mathrm{KH}_{2} \mathrm{PO}_{4}, \mathrm{CuSO}_{4} 5 \mathrm{H}_{2} \mathrm{O}$, $\mathrm{ZnSO}_{4} 7 \mathrm{H}_{2} \mathrm{O}$ and $\mathrm{MnSO}_{4} \mathrm{H}_{2} \mathrm{O}$, respectively. The soil was placed in 8-liters plastic pots at the rate of $7.5 \mathrm{~kg}^{-1}$ per pot. 
Twenty seeds of purslane (Portulaca oleracea L.) were then planted in the pots, and the soil was irrigated with deionised water twice a week to obtain the adequate field capacity. After fifteen days, the plants were thinned to 10 uniform stands in each pot. At two phases, upon thinning and upon the onset of inflorescence appearance, Fe was sprayed at the rates of 0.1 and $0.2 \%(\mathrm{w} / \mathrm{v})$ in the forms of synthetic Fe-ALA nano-complex (n[Fe(ALA) $\left.)_{3}\right]$ ) and Fe-EDDHA. Deionised water was also sprayed as control. Plants were reaped 12 weeks subsequent to planting. In shade, the plant samples were desiccated and prepared for the analysis.

Methanol extracts of the Purtulaca oleracae L. samples were prepared using the method described in Najafian and Zahedifar (2015). Twenty grams of dried samples were drenched in $250 \mathrm{ml}$ of methanol/water $(90: 10 \mathrm{v} / \mathrm{v})$ for $48 \mathrm{~h}$. The filtration and concentration of extracts was conducted in a rotary evaporator for ten minutes. Yields were recorded by weighting the fine powders. These were maintained at $-18^{\circ} \mathrm{C}$ before utilization. The required powder level in methanol was arranged before each measurement, following which the total phenol content and the antioxidant activity were evaluated.

Polyphenol extraction was carried out in view of the previous reports, albeit with a few changes (Justesen et al., 1998). The HPLC examination was conducted on the Agilent Technologies 1200 series (Germany), outfitted with Zorbax eclipse (XDB) $\mathrm{C}_{18}(5 \mu \mathrm{m}$ (ID), $4.6 \times 150 \mathrm{~mm}(\mathrm{FT})$ and a photodiode cluster identifier. Elution rates were observed at 230 and $280 \mathrm{~nm}$, by changing the solvent methanol to formic acid proportion.

The total phenolic compounds (TPC) in the purslane extract were measured by means of the Folin-Ciocalteu reagent. Using the method described by Halicia et al. (2005), the $1.2 \mathrm{ml}$ of $\mathrm{Na}_{2} \mathrm{CO}_{3}(7.5 \%, \mathrm{w} / \mathrm{v})$ solution and the $1.5 \mathrm{ml}$ of Folin-Ciocalteu's reagent (diluted 10 times) were added to $300 \mathrm{ml}$ of the samples. Mixtures of above compounds were then shaken and left for thirty minutes at ambient temperature. After that, the mixture absorbance was measured at $765 \mathrm{~nm}$ using a spectrophotometer (Varian 220, Australia). The measurements were performed 3 times. We tried to present the total phenol content as gallic acid (GAE) equivalent in $100 \mathrm{~g}$ of a fresh sample. For all TPC values, amendments were made by subtracting the ascorbic acid content (AAC) from the total phenol value.

The antioxidant activity was expressed by measuring the scavenging capacity of extract to cleanse synthetic free radical DPPH (Burits et al., 2001). $25 \mu \mathrm{l}$ of 12-3100 $\mu \mathrm{g}$ $\mathrm{ml}^{-1}$ gallic acid or methanol extracts were blended with 220 $\mu 1$ of $120 \mathrm{mmol} \mathrm{l}^{-1}$ radical solution of DPPH in methanol. The solutions were then retained at ambient temperature for around thirty minutes. The DPPH radical restraint was assessed at $515 \mathrm{~nm}$ by means of an EL $\times 808$ absorbance micro-plate reader (BioTek Instruments Inc., USA). IC $_{50}$ (concentration $\left(\mathrm{mg} \mathrm{l}^{-1}\right)$ was needed to restrain the DPPH radical formation by fifty percent. The sample values were computed on the basis of the nonlinear regression between mean \% radical-scavenging activity, utilizing MATLAB (The MathWorks Inc., USA) and log extract concentration $\left(\mu \mathrm{gmL}^{-1}\right)$. The methanol extract without DPPH was used as the blank. The antioxidant activity was assigned by way of the following equation:

Antioxidant activity $=1-\left[\left(A_{\text {sample }}-A_{\text {blank }}\right) / A_{\text {control }}\right] 100$,

where: $A_{\text {sample }}$ and $A_{\text {blank }}$ are absorption values of the test solution $(\mathrm{t}=30 \mathrm{~min})$ and the blank reaction $(\mathrm{t}=0 \mathrm{~min})$. DPPH (without plant extract) and methanol were separately utilized as a control and a blank.

Samples were first desiccated for $72 \mathrm{~h}$ at $70^{\circ} \mathrm{C}$ in an oven. Dried purslane samples were then powdered and kept in plastic vials. Nitrogen concentration of the shoot was determined by means of Autotech (Model 300). The samples ( $c a$. one gram per replicate) were subsequently ashed for $6 \mathrm{~h}$ at $550^{\circ} \mathrm{C}$. The white ash powder was added to 5 $\mathrm{ml}$ of $2 \mathrm{M}$ hot hydrochloric acid, filtered into a $50 \mathrm{ml}$ volumetric flask and with water, made up to $50 \mathrm{~mL}$. Iron and zinc analyses were conducted using an atomic absorption spectrophotometer (Model Varian 220, Australia), while, the concentrations of Sodium and potassium in the plant extracts were analyzed via a flame phytometer. In addition, magnesium and calcium concentrations were determined in the plant extracts using the inductively coupled plasma-mass spectrometry (ICP-MS, X-Series II; Thermo Fisher Scientific Inc., Waltham, MA, USA). Finally, via multiplying the weight of dry matter by nutrient mineral concentrations, the total amount of nutrients was calculated.

The statistical data analysis was carried out by means of the statistical program SPSS (version 20), in order to verify the significance of the distinctive treatments, while Duncan's multiple range test, at the $5 \%$ probability level, was utilized to compare the differences between the obtained means.

\section{RESULTS}

Our prime trials were focused on the specifications of the nano-sized iron complex. The FT-IR spectroscopy was used to determine the vibration characteristics of chemical functional groups. The FTIR of the resulting material showed an absorption pattern similar to amino acid ligands in the $500-4000 \mathrm{~cm}^{-1}$ region. In comparison with the free 5 -aminolevulinic acid, the N-H vibration bands in the Fe-ALA nano-complex shifted towards higher frequencies. The absorption band around $1575-1615 \mathrm{~cm}^{-1}$ in the 5 -aminolevulinic acid spectrum was attributed to the presence of a $\mathrm{C}=\mathrm{O}$ group and appeared be transferred to higher wave numbers in the Fe-ALA nano-complex spectra, including the $\mathrm{COOH}$ group in the covalent bonding to the iron (III) ion. The presence of iron is illustrated in the Fe-ALA nanocomplex via the energy dispersive X-ray analysis (EDX) nano-complex. The EDX spectrum also displays carbon, 
oxygen and nitrogen signals within the Fe-ALA nanocomplex (Fig. 1). Moreover, the transmission electron microscopy (TEM) image indicated that the iron particles size was within the span 5-20 nm, while the TEM image of the Fe-ALA nano-complex showed that the nanoparticles of $\mathrm{Fe}$, displaying close globular morphology, were arranged on the pectin surface with comparatively fine monodispersity (Fig. 2).

Fresh weight (FW), dry weight (DW), relative water content (RWC), and shoot and root lengths were measured over twelve weeks ( Fig. 3). The shoot dry weight, fresh weight and length of the purslane plants supplied with Fe-ALA nano chelates were greater as compared to the plants supplied with Fe-EDDHA. The shoot growth parameters of the purslane plants supplied with $n\left[\mathrm{Fe}(\mathrm{ALA})_{3}\right]$ at the $0.2 \%$ level were significantly greater than those of the plants supplied with the other rates of Fe fertilizers. The plants treated with $n\left[\mathrm{Fe}(\mathrm{ALA})_{3}\right]$ and $\mathrm{Fe}-\mathrm{EDDHA}$ at the rate of $0.2 \%$ had the highest root length. Both types of iron fertilizers significantly reduced the relative water content, with the untreated (control) plants having the highest level of water content.

The total polyphenolics and ascorbic acid content in the aerial parts of purslane plants was higher in the case of the $n\left[\mathrm{Fe}(\mathrm{ALA})_{3}\right]$ treatments, compared with the Fe-EDDHA treatments (Fig. 4). The purslane plants supplied with the Fe-ALA nano-complex at the level of $0.1 \%(w / v)$ had the highest TPC and AAC levels, compared with the plants sup-

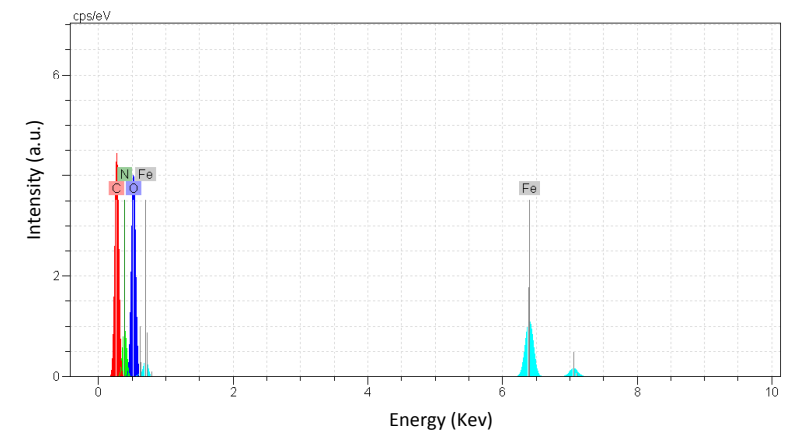

Fig. 1. EDX spectrum of the Fe-ALA nano-sized complex.

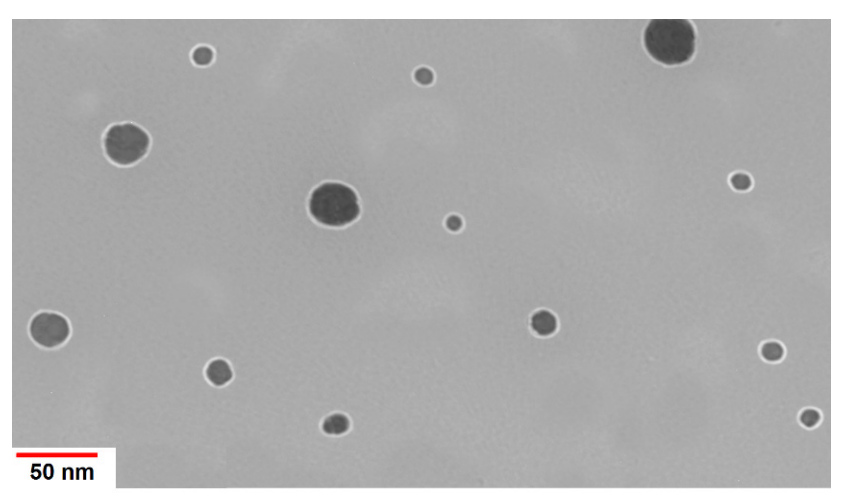

Fig. 2. TEM image of the Fe-ALA nano-sized complex. plied with higher concentrations or Fe-EDDHA. Finally, the total phenolics content was $367.26\left(\mathrm{mg} \mathrm{GAE} 100 \mathrm{~g}^{-1}\right)$,

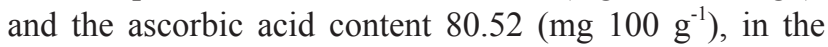
plants supplied with $0.1 \%(\mathrm{w} / \mathrm{v})\left[\mathrm{Fe}(\mathrm{ALA})_{3}\right]$ nano particles.

In this study, only 2 phenolic compounds were detected in the control plants, while the Fe-ALA nano-complex increased the number of detected compounds to five, including Catechin, Chlorogenic acid, Trans-ferulic acid, Hesperedin and Ellagic acid (Fig. 5). In contrast, fertilization with Fe-EDDHA raised the number of phenolics to 3

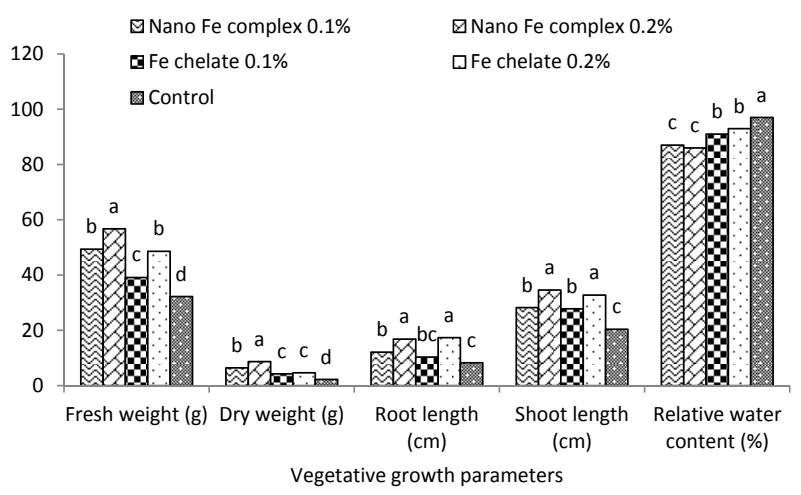

Fig. 3. Fresh weight, dry weight, shoot and root length, and relative water content. The columns in each parameter with the same letters are not significantly different according to the Duncan's test at $\mathrm{p} \leq 0.05$.

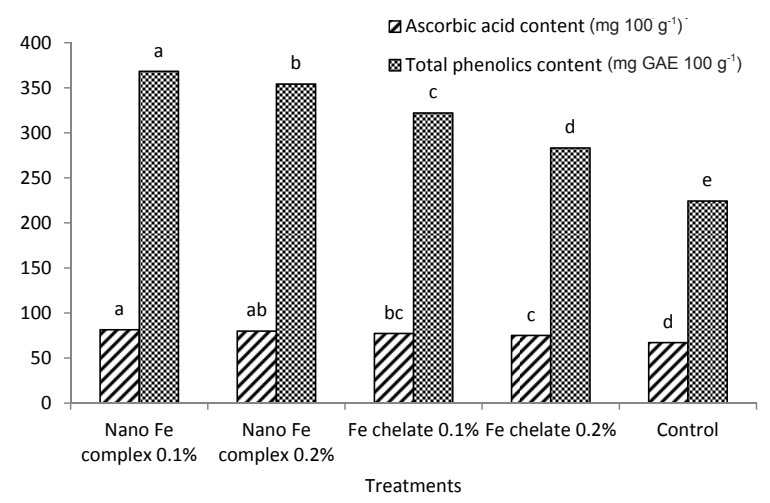

Fig. 4. Ascorbic acid and total phenolics contents for Purtulaca oleracea at different iron treatments. Explanations as in Fig. 3.

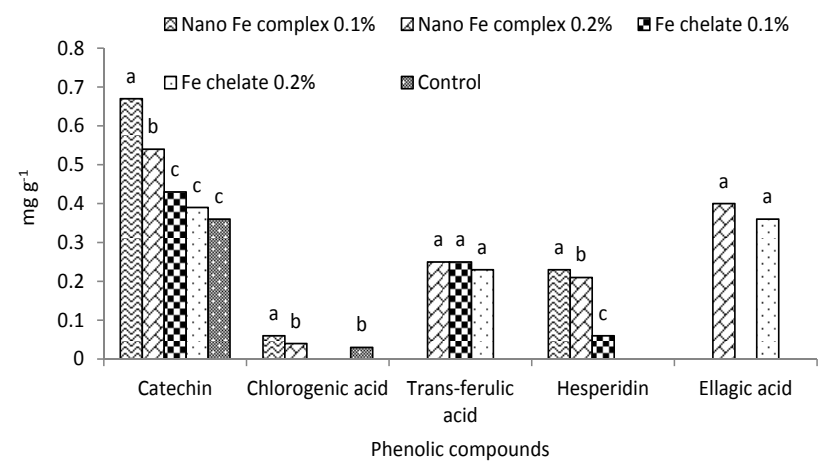

Fig. 5. Phenolic compounds in Purtulaca oleracea affected by iron fertilizers. Explanations as in Fig. 3. 
a

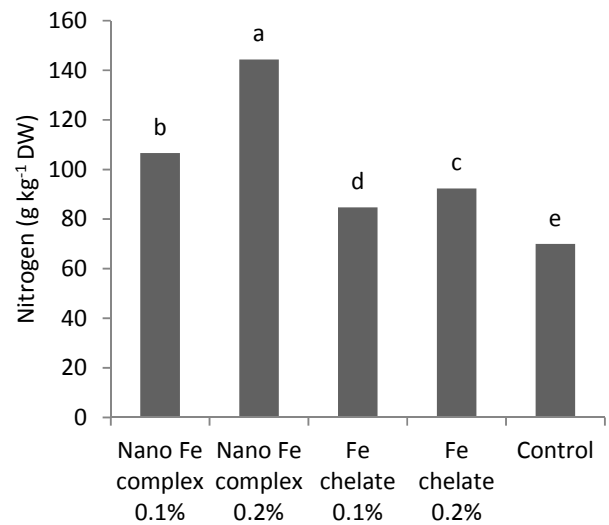

C
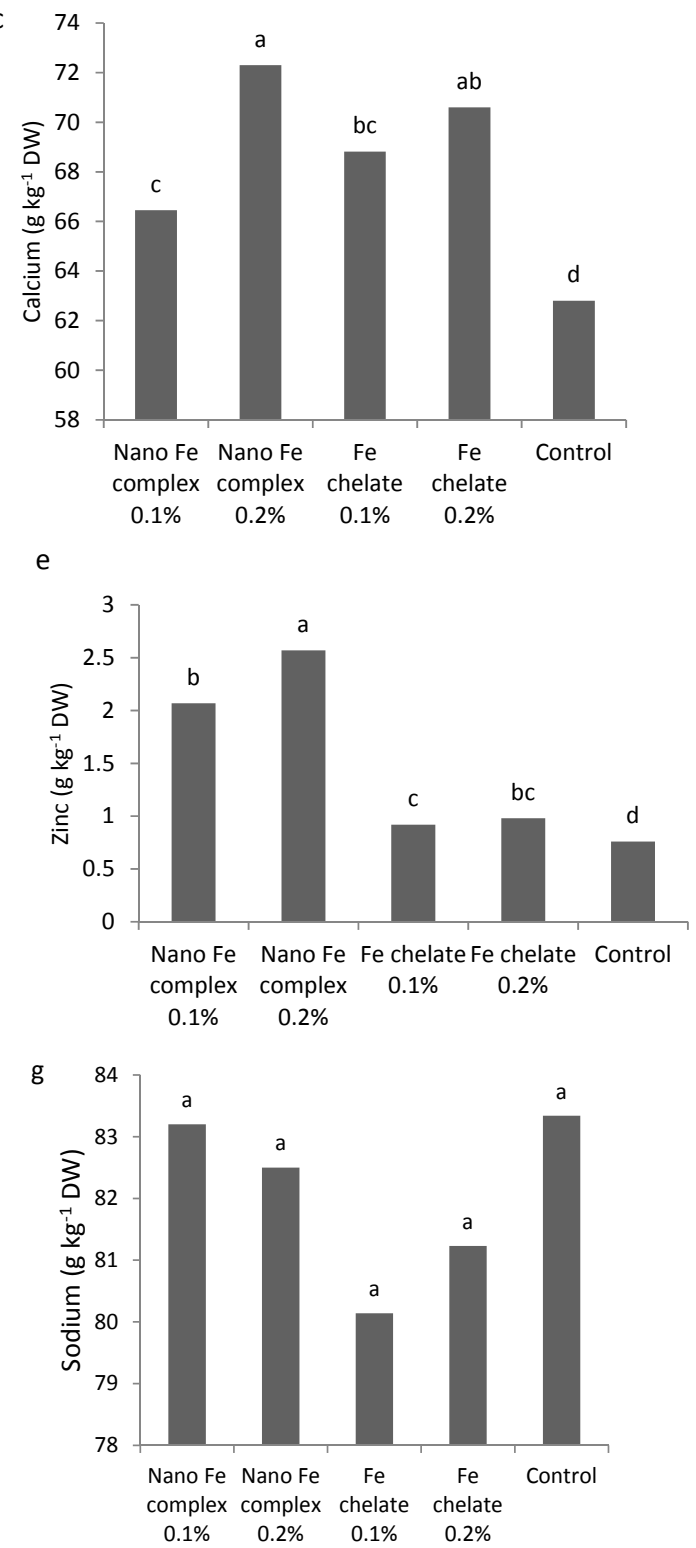

Fig. 6. Mineral concentrations: $\mathrm{a}$ - nitrogen, $\mathrm{b}$ - magnesium, $\mathrm{c}-$ calcium, $\mathrm{d}$ - iron, e - zinc, $\mathrm{f}$ - potassium, $\mathrm{g}$ - sodium in Portulaca oleracea at different levels of iron fertilization $\left(\mathrm{g} \mathrm{kg}^{-1} \mathrm{DW}\right)$. Explanations as in Fig. 3.
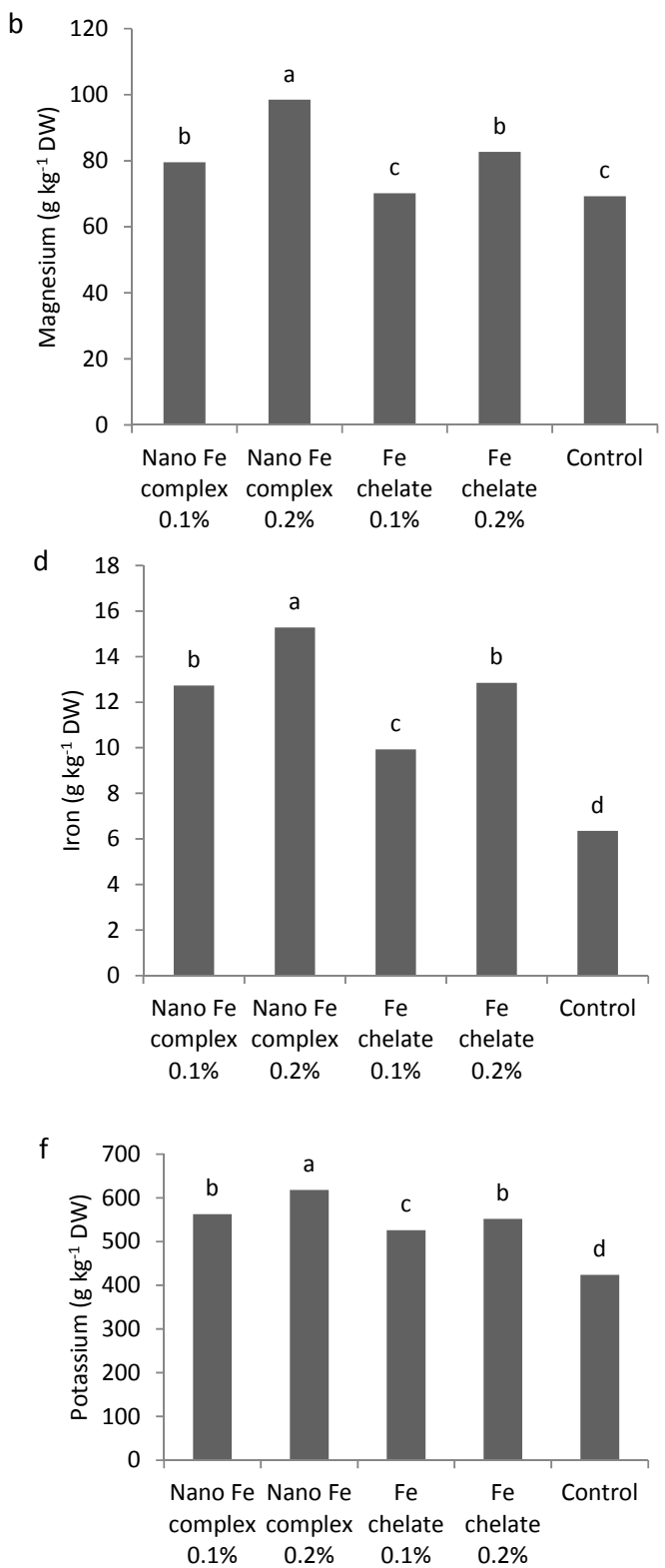

compounds, compared with non-treated plants. Catechin was the predominant phenolic compound in all purslane plants, contributing from $0.57 \mathrm{mg} \mathrm{g}^{-1}$ in treated plants with $\mathrm{n}\left[\mathrm{Fe}(\mathrm{ALA})_{3}\right]$ to $0.26 \mathrm{mg} \mathrm{g}^{-1}$ in the control plants.

The N, Mg, Ca, Fe, Zn, K, Na and contents in purslane shoots improved significantly in the treatments where Fe fertilizers (regardless of the actual Fe source) were applied, in comparison with the control plants (Fig. 6). However, no significant differences were observed between shoot $\mathrm{Na}$ concentrations in various Fe treatments. Among all treatments, the Fe nano-complex at the level of $0.2 \%$ $(\mathrm{w} / \mathrm{v})$ remained the best, as compared to other treatments which increased Fe up to 2.6 fold, over the control sample. The plants supplied with $\mathrm{n}\left[\mathrm{Fe}(\mathrm{ALA})_{3}\right]$ at $0.1 \%$, or with Fe-EDDHA at $0.2 \%$, also showed an increased shoot Fe content, up to $119 \%$, when compared with the control 


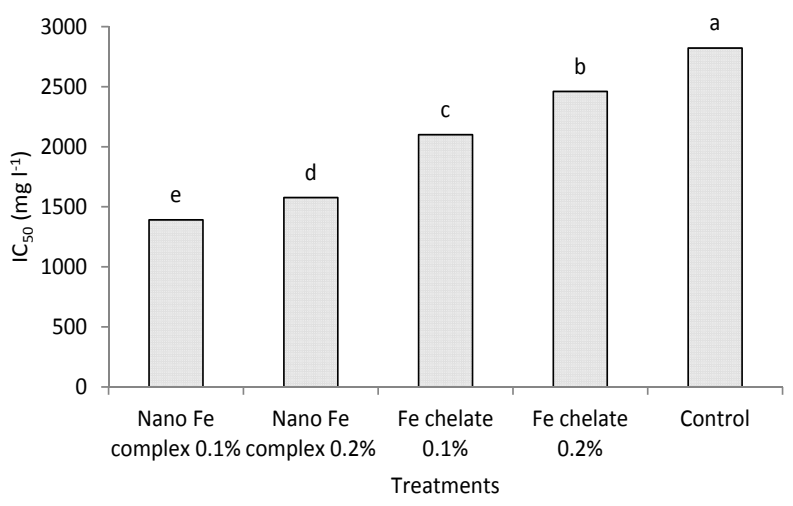

Fig. 7. Effects of the Fe nano-complex and Fe chelate applications on the antioxidant activity of Purtulaca oleracea, measured by DPPH assay (IC50 is the concentration required to inhibit DPPH radical formation by $50 \%$ ). Explanations as in Fig. 3.

group. Zinc concentration in purslane shoots ranged from $0.66 \mathrm{mmol} \mathrm{kg} \mathrm{m}^{-1} \mathrm{DW}$ in the control plants to $1.56 \mathrm{mmol}$ $\mathrm{kg}^{-1} \mathrm{DW}$ in the $\mathrm{n}\left[\mathrm{Fe}(\mathrm{ALA})_{3}\right]$ treated plants at $0.2 \%(\mathrm{w} / \mathrm{v})$, $\mathrm{Zn}$ concentration increased to 136 and 47\%, respectively, when the $0.2 \%$ of $\mathrm{n}\left[\mathrm{Fe}(\mathrm{ALA})_{3}\right]$ and $\mathrm{Fe}-\mathrm{EDDHA}$, were applied. Iron applied with $0.2 \%(\mathrm{w} / \mathrm{v})$ of $\mathrm{n}\left[\mathrm{Fe}(\mathrm{ALA})_{3}\right]$ and Fe-EDDHA enhanced the $\mathrm{N}$ concentration to 107 and $32 \%$, respectively, as compared with the untreated plants (the control group). The highest shoot $\mathrm{N}$ content was achieved by the application of the Fe nano-complex at $0.2 \%$ concentration. The purslane plants supplied with the Fe(III)-ALA nano chelate accumulated higher shoot $\mathrm{Mg}, \mathrm{Ca}$ and $\mathrm{K}$ contents in comparison with those supplied with Fe-EDDHA. The Fe nano-complex at the level of $0.2 \%$ was more effective than the lower concentration. Augmentations in the shoot $\mathrm{Mg}$ content up to 43 and $19 \%$, in the shoot Ca content up to 15 and $12 \%$, and in the shoot $\mathrm{K}$ content up to 46 and $30 \%$, were achieved by applying $0.2 \%$ concentrations of $\mathrm{n}\left[\mathrm{Fe}(\mathrm{ALA})_{3}\right]$ and $\mathrm{Fe}-\mathrm{EDDHA}$, respectively.

The antioxidant activity is the result of the active compounds occurring in plants. The antioxidant activity of purslane plant extracts is exhibited in Fig. 7 with the equation of regression $\left(\mathrm{r}^{2}\right)$ of $\alpha$-tocopherol, gallic acid and the quercetin standard curve. The value of $\mathrm{IC}_{50}$ for the purslane plant extract, which was treated with Fe fertilizers in the current trial, was assessed. It was found to range between $1389.44 \pm 5.82$, and $2820.71 \pm 5.12 \mathrm{mg} \mathrm{l}^{-1}$. Te greatest antioxidant activity $\left(1389.44 \mathrm{mg} \mathrm{l}^{-1}\right.$ ) was displayed by the purslane plants treated with $0.2 \% \mathrm{n}\left[\mathrm{Fe}(\mathrm{ALA})_{3}\right]$, whereas the lowest $\left(2820.71 \mathrm{mg} \mathrm{l}^{-1}\right.$ ) was found in the control group. These findings reveal that purslane plants are characterised with a significant antioxidant activity potential and can be used as natural antioxidants in pharmacology.

\section{DISSCUSION}

The results obtained in several studies indicate the definite effect of the amino acids application on enhancing the growth rates of certain crops (Hoque et al., 2007;
Kursat et al., 2007). A possible reason behind the Fe-amino acid nano chelate effect related to improving the purslane plants growth is maintaining the hormone balance within plant tissues (Nassar et al., 2003). Iron nano fertilizers have stimulatory effects on plant growth. The stimulating effect of the Fe nano chelate fertilizer applications the growth of peanut shoots and roots (Rui et al., 2016), mung bean (Karimi et al., 2014), saffron (Maleki Farahani et al., 2015) and poinsettia (Kaviani et al., 2016) has been reported. The increased $\mathrm{Fe}$ and carbohydrate availability in the Fe treated plants might be the reason for their increased shoot and root growth.

In the present study, the foliar application of the Fe nano-complex significantly improved the mineral nutrient contents in purslane plant shoots. The mineral ions accumulation in plant cells was found to improve osmotic regulation, enhance the synthesis of proteins, and maintain root membrane integrity (Essa, 2002). Our results are consistent with the findings of Van Nhan et al. (2016), in which nutrients such as $\mathrm{Na}, \mathrm{Ca}$ and $\mathrm{K}$ in non-transgenic and transgenic cotton increased with the application of $\mathrm{Fe}_{2} \mathrm{O}_{3}$ nanoparticles. Cuin and Shabala (2007) revealed that predominant amino acids diminished $\mathrm{K}$ leakage in plant roots by ameliorating the integrity of cell membranes and root $\mathrm{K}$ influx regulation. The enhanced shoos potassium and nitrogen contents in the purslane plants supplied with $\mathrm{Fe}(\mathrm{III})-\mathrm{ALA}$ chelate, in comparison with those treated with Fe-EDDHA, confirm the amino acid (5-aminolevulinic acid) role in improving the cell membrane integrity and function. The elevated shoot Fe and $\mathrm{Zn}$ uptake in the purslane plants supplied with the Fe-ALA nano chelate might partly be due to increased $\mathrm{N}$ uptake. An improved $\mathrm{N}$ nutrition status increases the activity and number of Fe-transporter proteins within the root cell membranes and, as a result, enhances the root Fe uptake (Murata et al., 2008). 5-ALA might also foster $\mathrm{Fe}$ acquisition by purslane leaves. Aminolevulinic acid is absorbed via transport proteins containing amino acid permease 5(AAP5), amino acid permease 1 (AAP1) and lysine-histidine (LHT1) (Svennerstam et al., 2007). Our finding was also supported by Gui et al. (2015) who showed a significant Fe content in both non-transgenic and transgenic rice, following the application of $\mathrm{Fe}_{2} \mathrm{O}_{3}$ nanoparticles. However, as regards the Fe-amino acid nano chelate uptake mechanism, it is still unclear whether the Fe-amino acid nano chelate can get into the root cell cytoplasm, due to its size, as a non-dissociated complex, or whether it first dissociates as free amino acid and Fe at the root surface and then passes through the cell membrane. This possibility needs to be tested through isotopic (labelled Fe and N) studies. Based on the TEM data, the diameter of the Fe-ALA nano chelate molecules (Fig. 2) is smaller than the cell wall pore diameter (less than $5 \mathrm{~nm}$ ). Thus, no limitations seem to be placed on the movement of the Fe-ALA nano chelate by these free spaces within the cell membrane. 
Phenolic compounds form a class of antioxidant agents which act as free radical scavengers. They are responsible for the antioxidant activity in medicinal plants. Extracts of many plants containing phenolics display effective antioxidant attributes, inhibit free radical damage (Koleva et al., 2002) and show antimutagenic, antitumor and antioxidant physiological activity (Li et al., 2006). The potential oxidative stress inhibition of phenolic compounds, found in dietary and medicinal plants (Manach et al., 2004), as well as phenolic compounds from many traditional Iranian medicines, showed both antioxidation and antiglycation properties. Phenolic compounds can be directly used to scavenge reactive oxygen species (ROS) and $\mathrm{OH}$ (Omidbeigi, 2008).

In the plant growth process, the enhanced availability of micronutrients displays a significant phenolic accumulation potential (Parr and Bolwell, 2000). Benzon et al. (2015) revealed that the TPC in white rice cultivars can be enhanced through the application of nano-fertilizers. In another study, Alizadeh et al. (2010) implied that the highest total phenolic content was found in $1000 \mathrm{mg} /$ plant fertilizer treatment. The results of the present study showed that total phenolic content was associated with the antioxidant activity and ascorbic acid content. The correlation coefficients obtained were 0.957 (antioxidant activity) and 0.974 (ascorbic acid content). Erkan et al. (2008) revealed a close correlation between the total phenolic content and the radical scavenging activity of extracts obtained from various natural sources. Ascorbic acid (vitamin C) has been reported to possess antioxidant activity because of its potential to neutralize free radicals and ability to inhibit cancer and cardiovascular disease (Uddin et al., 2014).

Catechin is a flavan-3-ol that belongs to the flavonoid group. Catechin is an effective ROS scavenger and may also act indirectly as an antioxidant through its effect on enzyme activities and transcription factors (Higdon and Frei, 2003). Nano iron applications had outstandingly positive effects on the phenolic content. The Fe nano-complex at the rate of $0.1 \%$ incited a significantly higher phenolic content, in comparison with both the control plants and the plants treated with Fe-EDDHA fertilizers (Fig. 5). Consistently with our findings, Njogu et al. (2014) revealed that the foliar application of micro elements on tea plants increased the polyphenol content. The increase in the polyphenol content due to the foliar application of iron results from the increasing leaf activity since this nutrient is applied only in those regions where photosynthesis takes place. Hence, this element can be rapidly transformed into the compounds that prove necessary for plant growth. The latest studies have shown that the foliar application of fertilizers increases total leaf polyphenols, which can be attributed to the presence of micro elements in the foliar fertilization process (Obatolu, 1999). Rui et al. (2016) reported that Fe nano particles induced protection mechanisms to scavenge reactive oxygen by increasing of the level of polyphenols in peanut leaves. Adversely, a major decrease in the polyphenol contents in maize grain was recorded when Fe was applied in soil (Ramzani et al., 2016).

Along with the amplification of the shoot polyphenolic content, exposure to the $\mathrm{Fe}$ nano-complex increased antioxidant activity in purslane plant shoots. In agreement with our findings, Benzon et al. (2015) demonstrated that nano-fertilizer application enhanced both the DPPH scavenging activity and antioxidant potential in rice. Delfani et al. (2014) revealed that the application of nano-fertilizers was supplemental, and their superior absorption by plant cells in some way supplied sufficient nutrients to increase antioxidant activity in black-eyed peas. In addition, recent studies have shown that the application of nanoscale fertilizers in peanut (Prasad et al., 2012) and soya bean (Lu et al., 2002) enhance antioxidant activity. In various plants, phenolic compounds and ascorbic acid have been shown to be correlated with antioxidant activity (López-Vélez et al., 2003). The activity of polyphenols as prominent antioxidants has been ascribed to different mechanisms, including the transition ion catalysts binding, the prevention of chain initiation, the blockage of successive hydrogen abduction, the decomposition of peroxides, radical scavenging and lessening capacity (Yildirim et al., 2001). Thus, increasing the polyphenolics and ascorbic acid contents by applying the Fe-ALA nano-complex could be a useful method to enhance antioxidant activity and, hence, to maximise the pharmaceutical properties of purslane plants.

\section{CONCLUSIONS}

1. The application of nanoparticle fertilizers is an effective method, via its high site specificity and reduced collateral damage.

2. The results obtained show that the foliar application of the $\mathrm{Fe}(\mathrm{III})$-aminolevulinic acid nano chelate (as a Fe source) increase the shoot $\mathrm{Fe}, \mathrm{Zn}, \mathrm{N}, \mathrm{Mg}, \mathrm{Ca}$ and $\mathrm{K}$ contents and improve the growth rates of purslane plants, in comparison with Fe-EDDHA. The maintenance of the root cell membrane integrity appears to be the main reason behind the high nutrients uptake under $\mathrm{n}\left[\mathrm{Fe}(\mathrm{ALA})_{3}\right]$ treatments.

3. An improved $\mathrm{N}$ nutrition status, as well as elevated shoot growth, could partly explain the positive effect of the Fe-ALA nano chelate in improving antioxidant activity and polyphenol content in purslane plants.

4. In accordance with the obtained results, the Fe(III)aminolevulinic acid nano chelate can be used as a novel chelate to supply $\mathrm{Fe}$, and to increase the pharmaceutical and nutritional values of Portulaca oleracea L. (in Persian Khorfeh), which is an extremely popular Iranian vegetable.

5. To realize the mechanism of action of the applied nanoscale materials, specific studies have to be carried out. In addition, the most effective application method needs to be appraised. 


\section{ACKNOWLEDGEMENTS}

I would like to thank Ms. Atefeh Bahmanzadegan for her technical assistance in using the laboratory instruments and analytical measurements.

Conflict of interest: The Author declares no conflict of interest.

\section{REFERENCES}

Alizadeh A., Khoshkhui M., Javidnia K., Firuzi O., Tafazoli E., and Khalighi A., 2010. Effects of fertilizer on yield, essential oil composition, total phenolic content and antioxidant activity in Satureja hortensis L. (Lamiaceae) cultivated in Iran. J. Med. Plants Res., 4(1), 33-40.

Benzon H.R.L., Rubenecia M.R.U., Ultra V.U., and Lee J.S.Ch., 2015. Nano-fertilizer affects the growth, development, and chemical properties of rice. Int. J. Agron. Agr. Res., 7(1), 105-117.

Burits M., Asres K., and Bucar F., 2001. The antioxidant activity of the essential oils of Artemisia afra, Artemisia abyssinica and Juniperus procera. Phytotherapy Res., 15, 103-108.

Cuin T.A. and Shabala S., 2007. Amino acids regulate salinityinduced potassium efflux in barley root epidermis. Planta, 225, 753-761.

Delfani M., Firouzabadi M.B., Farrokhi N., and Makarian H., 2014. Some physiological responses of black-eyed pea to iron and magnesium nanofertilizers. Commun. Soil Sci. Plant Anal., 45, 530-540.

Erkan N., Akgonen S., Ovat S., Goksel G., and Ayranci E., 2011. Phenolic compounds profile and antioxidant activity of Dorystoechas hastata L. Boiss et Heldr. Food Res. Int. 44, 3013-3020.

Essa T.A., 2002. Effect of salinity stress on growth and nutrient composition of three soybean (Glycine $\max$ L. Merrill) cultivars. J. Agron. Crop Sci., 188, 86-93.

Fageria N.K., Baligar V.C., and Wright R.J., 1990. Iron nutrition of plants: an overview on the chemistry and physiology of its deficiency and toxicity. Pesq. Agropec. Bras. Brasflia, 25(4), 553-570.

Ghasemi S., Khoshgoftarmanesh A.H., Hadadzadeh H., and Afyuni M., 2014. Synthesis, characterization, theoretical and experimental investigations of zinc (II)-amino acid complexes as ecofriendly plant growth promoters and highly bioavailable sources of zinc. J. Plant Growth Regul., 32, 315-323.

Gui X., Deng Y., Rui Y., Gao B., Luo W., Chen Sh., Van Nhan L.V., Li X., Liu Sh., Han Y., Liu L., and Xing B., 2015. Response difference of transgenic and conventional rice (Oryza sativa) to nanoparticles $\left(\gamma \mathrm{Fe}_{2} \mathrm{O}_{3}\right)$. Environ. Sci. Pollut. Res., 22, 17716-17723.

Halicia M., Odabasoglua F., Suleymanb H., Cakirc A., Asland A., and Bayir Y., 2005. Effects of water extract of Usnea longissima on antioxidant enzyme activity and mucosal damage caused by indomethacin in rats. Phytomed., 12, 656-662.

Higdon J.V. and Frei B., 2003. Tea Catechins and polyphenols: health effects, metabolism, and antioxidant functions. Critical Rev. Food Sci. Nutr., 43(1), 89-143.

Hoque M.A., Banu M.N.A., Okuma E., Amako K., Nakamura Y., Shimoishi Y., and Murata Y., 2007. Exogenous proline and glycinebetaine ingresses $\mathrm{NaCl}$-induced ascorbate glutathione cycle enzyme activities and proline improves salt tolerance more than glycinebetaine in tobacco Bright yellow-2 suspension-cultured cells. J. Plant Physiol., 164, 553-561.

Justesen U., Knuthsen P., and Leth T., 1998. Quantitative analysis of flavonols, flavones, and flavanones in fruits, vegetables and beverages by high performance liquid chromatography with photo-diode array and mass spectrometric detection. J. Chroma, A, 799, 101-110.

Karimi Z., Pourakbar L., and Feizi H., 2014. Comparison effect of nano-iron chelate and iron chelate on growth parameters and antioxidant enzymes activity of mung bean (Vigna radiate L.). Adv. Environ. Biol., 8(13), 916-930.

Kaviani B., Vali Fakouri Ghaziani M., and Negahdar N., 2016. The effect of iron nano-chelate fertilizer and cycocel (CCC) on some quantity and quality characters of Euphorbia pulcherrima Willd. J. Med. Bioengineer., 5(1), 41-44.

Knekt P., Jarvinen R., Reunanen A., and Maatela J., 1996. Flavonoid intake and coronary mortality in Finland: a cohort study. British Med. J., 312, 478-481.

Koleva L.L., Van Beek T.A., Linssen J.P.H., De Groot A., and Evstatieva L.N., 2002. Screening of plant extracts for antioxidant activity: A comparative study on three testing methods. Phytochem. Analys., 13, 8-17.

Kursat C., Semra K., and Kudret K., 2007. Some morphological and anatomical observations during alleviation of salinity $(\mathrm{NaCl})$ stress on seed germination and seedling growth of barley by polyamines. Acta Physiol. Plant, 29, 551-557.

Li B.B., Smith B., and Hossain M.M., 2006. Extraction of phenolics from citrus peles: I. solvent extraction method. Sep. Purif. Technol., 48, 182-188.

Liu L., Howe P., Zhou Y.F., Xu Z.Q., Hocart C., and Zhang R., 2000. Fatty acids and $\beta$-carotene in Australian purslane (Portulaca oleracea) varieties. J. Chromato., A, 893, 207-213.

López-Vélez M., Martínez-Martínez F., and Del Valle-Ribes C., 2003. The study of phenolic compounds as natural antioxidants in wine. Crit. Rev. Food Sci. Nutr. 43(3), 233-244. doi: 10.1080/727072831

Lu C.M., Zhang C.Y., Wen J.Q., Wu G.R., and Tao M.X., 2002. Research on the effect of nanometer materials on germination and growth enhancement of Glycine max and its mechanism. Soybean Sci., 21(3), 68-172.

Maleki Farahani S., Khalesi A., and Sharghi Y., 2015. Effect of nano iron chelate fertilizer on iron absorption and saffron (Crocus sativus L.) quantitative and qualitative characteristics. Asian J. Biological Sci., 8(2), 72-82.

Manach C., Scalbert A., Morand C., Remesy C., and Jimenez L., 2004. Polyphenols: food sources and bioavailability. Am. J. Clin. Nutr., 79, 727-747.

Metsarinne S., Rantanen P., Aksela R., and Tuhkanen T., 2004. Biological and photochemical degradation rates of diethylene triamine penta acetic acid (DTPA) in the presence and absence of Fe(III). Chemosphere, 55, 379-388.

Murata Y., Harada E., Sugase K., Namba K., Horikawa M., Ma J.F., Yamaji N., Ueno D., Nomoto K., Iwashita T., and Kusumoto S., 2008. Specific transporter for iron(III)phytosiderophore complex involved in iron uptake by barley roots. Pure Appl. Chem., 80, 2689-2697. 
Naderi M.R. and Danesh Shahraki A., 2011. Nano-fertilizers and their role in agriculture. Takta J., 86, 66-73.

Najafian Sh. and Zahedifar M., 2015. Antioxidant activity and essential oil composition of Satureja hortensis L. as influenced by sulfur fertilizer. J. Sci. Food Agr., 95(12), 2404-2408.

Nassar A.H., El-Tarabily K.A., and Sivasithamparam K., 2003. Growth promotion of bean (Phaseolus vulgaris L.) by a polyamine-producing isolate of Streptomyces griseoluteus. Plant Growth Regul., 40, 97-106.

Njogu R.E.N., Kariuki D.K., Kamau D.M., and Wachira F.N., 2014. Relationship between tea (Camellia sinensis) leaf uptake of major nutrients, nitrogen, phosphorous and potassium (NPK) and leaf anatomy of different varieties grown in the Kenyan highlands. BEST: Int. J. Humanities, Arts, Med. Sci., 2(8), 95-102.

Obatolu C.R., 1999. Correction of magnesium deficiency in tea plants through foliar applications. Commun. Soil Sci. Plant Anal., 30, 1649-1655.

Omid beige R., 2008. Approaches to the production and processing of medicinal plants (in Persian). Press Designers Publication, 1, 283, Tehran, Iran.

Parr A.J. and Bolwell G.P., 2000. Phenols in the plant and in man. The potential for possible nutritional enhancement of the diet by modifying the phenols content or profile. J. Sci. Food Agr., 80, 985-1012.

Percival M., 1998. Antioxidants. Clin. Nutr. Insight, 31, 1-4.

Prasad T.N.V.K.V., Sudhakar P., Sreenivasulu Y., Latha P., Munaswamy V., Raja Reddy K., Sreeprasad T.S., Sajanlal P.R., and Pradeep T., 2012. Effect of nanoscale zinc oxide particles on the germination, growth and yield of peanut. J. Plant Nutr., 35(6), 905-927.

Ramzani P.M.A., Khalid M., Anjum Sh., Khan W.D., Iqbal M., and Kausar S., 2016. Improving iron bioavailability and nutritional value of maize (Zea mays L.) in sulfur-treated calcareous soil, Arch. Agron. Soil Sci., DOI: 10.1080/03650340.2016.1266484

Rodríguez-Lucena P., Hernández-Apaolaza L., and Lucena J.J., 2010. Comparison of iron chelates and complexes sup- plied as foliar sprays and in nutrient solution to correct iron chlorosis of soybean. J. Plant Nutr. Soil Sci., 173, 120-126, 10.1002/jpln.200800256

Rui M., Ma Ch., Hao Y., Guo J., Rui Y., Tang X., Zhao Q., Fan X., Zhang Z., Hou T., and Zhu S., 2016. Iron oxide nanoparticles as a potential iron fertilizer for peanut (Arachis hypogaea). Frontiers Plant Sci., 7, Article 815

Svennerstam H., Ganeteg U., Bellini C., and Näsholm T., 2007. Comprehensive screening of Arabidopsis mutants suggests the lysine histidine transporter 1 to be involved in plant uptake of amino acids. Plant Physiol., 143(4), 1853-1860.

Uddin K., Juraimi A.Sh., Hossain S., Nahar A.U., Ali E., and Rahman M.M., 2014. Purslane weed (Portulaca oleracea): A prospective plant source of nutrition, omega-3 fatty acid, and antioxidant attributes. Sci. World J., 2014, ID 951019, http://dx.doi.org/10.1155/2014/951019

Vadas T.M., Zhang X., Curran A.M., and Ahner B.A., 2007. Fate of DTPA, EDTA and EDDS in hydroponic media and effects on plant mineral nutrition. J. Plant Nutr., 30, 1229-1246.

Van Nhan L., Ma C., Rui Y., Cao W., Deng Y., Liu L., and Xing B., 2016. The effects of $\mathrm{Fe}_{2} \mathrm{O}_{3}$ nanoparticles on physiology and insecticide activity in non-transgenic and bt-transgenic cotton. Front. Plant Sci., 6, 1263, https://doi.org/10.3389/ fpls.2015.01263

Wei Y., Fang Z., Zheng L., Tan L., and Tsang E. P., 2016. Green synthesis of $\mathrm{Fe}$ nanoparticles using Citrus maxima peels aqueous extracts. Materials Letters, 185, 384-386.

Xiang L., Xing D., Wang W., Wang R., Ding Y., and Du L., 2005. Alkaloids from Portulaca oleracea L. Phytochem., 66, 2595-2601.

Yildirim A., Mavi A., and Kara A.A., 2001. Determination of antioxidant and antimicrobial activities of Rumex crispus L. extracts. J. Agr. Food Chem., 49, 4083-4089.

Yousefzadeh S. and Sabaghnia N., 2016. Nano-iron fertilizer effects on some plant traits of dragonhead (Dracocephalum moldavica L.) under different sowing densities. Acta Agri. Slovenica, 107, 429-437. 